\title{
The ALMA-PILS survey: First detection of nitrous acid (HONO) in the interstellar medium
}

\author{
A. Coutens ${ }^{1}$, N. F. W. Ligterink ${ }^{2}$, J.-C. Loison ${ }^{3}$, V. Wakelam ${ }^{1}$, H. Calcutt ${ }^{4}$, M. N. Drozdovskaya ${ }^{2}$, J. K. Jørgensen ${ }^{5}$, \\ H. S. P. Müller ${ }^{6}$, E. F. van Dishoeck ${ }^{7,8}$, and S. F. Wampfler ${ }^{2}$ \\ ${ }^{1}$ Laboratoire d'astrophysique de Bordeaux, Univ. Bordeaux, CNRS, B18N, allée Geoffroy Saint-Hilaire, 33615 Pessac, France \\ e-mail: audrey.coutens@u-bordeaux.fr \\ 2 Center for Space and Habitability (CSH), University of Bern, Sidlerstrasse 5, 3012 Bern, Switzerland \\ 3 Institut des Sciences Moléculaires (ISM), CNRS, Université Bordeaux, 351 cours de la Libération, 33400 Talence, France \\ ${ }^{4}$ Department of Space, Earth and Environment, Chalmers University of Technology, 41296 Gothenburg, Sweden \\ 5 Centre for Star and Planet Formation, Niels Bohr Institute and Natural History Museum of Denmark, University of Copenhagen, \\ Øster Voldgade 5-7, 1350 Copenhagen K, Denmark \\ 6 I. Physikalisches Institut, Universität zu Köln, Zülpicher Str. 77, 50937 Köln, Germany \\ 7 Leiden Observatory, Leiden University, PO Box 9513, 2300 RA Leiden, The Netherlands \\ 8 Max-Planck Institut für Extraterrestrische Physik (MPE), Giessenbachstr. 1, 85748 Garching, Germany
}

Received 10 January 2019 / Accepted 7 March 2019

\begin{abstract}
Nitrogen oxides are thought to play a significant role as a nitrogen reservoir and to potentially participate in the formation of more complex species. Until now, only $\mathrm{NO}, \mathrm{N}_{2} \mathrm{O}$, and $\mathrm{HNO}$ have been detected in the interstellar medium. We report the first interstellar detection of nitrous acid (HONO). Twelve lines were identified towards component B of the low-mass protostellar binary IRAS 162932422 with the Atacama Large Millimeter/submillimeter Array, at the position where $\mathrm{NO}$ and $\mathrm{N}_{2} \mathrm{O}$ have previously been seen. A local thermodynamic equilibrium model was used to derive the column density $\left(\sim 9 \times 10^{14} \mathrm{~cm}^{-2}\right.$ in a 0 '. 5 beam) and excitation temperature $(\sim 100 \mathrm{~K})$ of this molecule. $\mathrm{HNO}, \mathrm{NO}_{2}, \mathrm{NO}^{+}$, and $\mathrm{HNO}_{3}$ were also searched for in the data, but not detected. We simulated the $\mathrm{HONO}$ formation using an updated version of the chemical code Nautilus and compared the results with the observations. The chemical model is able to reproduce satisfactorily the $\mathrm{HONO}, \mathrm{N}_{2} \mathrm{O}$, and $\mathrm{NO}_{2}$ abundances, but not the $\mathrm{NO}, \mathrm{HNO}$, and $\mathrm{NH}_{2} \mathrm{OH}$ abundances. This could be due to some thermal desorption mechanisms being destructive and therefore limiting the amount of $\mathrm{HNO}$ and $\mathrm{NH}_{2} \mathrm{OH}$ present in the gas phase. Other options are UV photodestruction of these species in ices or missing reactions potentially relevant at protostellar temperatures.
\end{abstract}

Key words. astrochemistry - stars: formation - stars: protostars - ISM: molecules - ISM: individual objects: IRAS $16293-2422$

\section{Introduction}

The interstellar medium (ISM) is characterised by a rich and varied chemistry with closely connected groups of species found to be prominent in regions with differing physics. An example is the group of nitrogen oxides, i.e. molecules containing nitrogenoxygen-hydrogen bonds. Secure interstellar detections have been made for three molecules: nitric oxide (NO; e.g. Liszt \& Turner 1978; McGonagle et al. 1990; Ziurys et al. 1991; Caux et al. 2011; Codella et al. 2018; Ligterink et al. 2018), nitrosyl hydride (HNO; Snyder et al. 1993) and nitrous oxide $\left(\mathrm{N}_{2} \mathrm{O}\right.$; Ziurys et al. 1994; Ligterink et al. 2018). These species, in particular NO, are thought to be critical for the overall nitrogen chemistry of the ISM as they may lock up significant amounts of atomic nitrogen, and are often only second in abundance to molecular nitrogen (e.g. Herbst \& Leung 1986; Nejad et al. 1990; Pineau des Forêts et al. 1990; Visser et al. 2011). Nitrogen oxides can be at the basis of greater chemical complexity, as demonstrated, for example, with the solid-state hydrogenation of NO into hydroxylamine $\left(\mathrm{NH}_{2} \mathrm{OH}\right.$; Congiu et al. 2012; Fedoseev et al. 2012, 2016) or energetic processing of $\mathrm{N}_{2} \mathrm{O}$ ice (de Barros et al. 2017).
Despite the relevance of nitrogen oxides as a nitrogen reservoir and as precursors of complex molecules, a number of important members of this group have not yet been detected in the ISM. Examples are nitrogen dioxide $\left(\mathrm{NO}_{2}\right)$, nitrous acid ( $\mathrm{HONO})$, and nitric acid $\left(\mathrm{HNO}_{3}\right)$, which on Earth play a role in atmospheric pollution (e.g. Possanzini et al. 1988). In particular, the photodissociation of HONO results in abundant formation of $\mathrm{OH}$ radicals, which in turn engage in various oxidation reactions and the formation of ground-level ozone $\left(\mathrm{O}_{3}\right.$; Ren et al. 2003; Lee et al. 2013; Gligorovski 2016; Zhang et al. 2016). Because of its relevance in atmospheric chemistry, the formation, destruction, and characteristics of HONO have been well studied (e.g. Cox \& Derwent 1976; Jenkin et al. 1988; Joshi et al. 2012).

In this work, $\mathrm{HONO}$ and other nitrogen oxides were searched for towards the low-mass protostar IRAS 16293-2422 (hereafter IRAS 16293), located at a distance of $\sim 140 \mathrm{pc}$ in the $\rho$ Ophiuchus cloud complex (Dzib et al. 2018). This Class 0 object is known for its chemical complexity and is considered an astrochemical reference among solar-type protostars (e.g. van Dishoeck et al. 1995; Cazaux et al. 2003; Caux et al. 2011; Jørgensen et al. 2016). A large number of species have 
first been detected towards a low-mass source in this object. These detections include the small species $\mathrm{NO}$ and $\mathrm{N}_{2} \mathrm{O}$ (Caux et al. 2011; Ligterink et al. 2018), the simplest "sugar" glycolaldehyde $\left(\mathrm{HOCH}_{2} \mathrm{CHO}\right.$; Jørgensen et al. 2012, 2016), the peptide-like molecules formamide $\left(\mathrm{NH}_{2} \mathrm{CHO}\right)$ and methyl isocyanate $\left(\mathrm{CH}_{3} \mathrm{NCO}\right.$; Kahane et al. 2013; Coutens et al. 2016; Ligterink et al. 2017; Martín-Doménech et al. 2017), cyanamide $\left(\mathrm{NH}_{2} \mathrm{CN}\right.$; Coutens et al. 2018), methyl isocyanide $\left(\mathrm{CH}_{3} \mathrm{NC}\right.$; Calcutt et al. 2018), ethylene oxide $\left(\mathrm{c}-\mathrm{C}_{2} \mathrm{H}_{4} \mathrm{O}\right.$, Lykke et al. 2017), and the isomers of acetone $\left(\mathrm{CH}_{3} \mathrm{COCH}_{3}\right)$ and propanal $\left(\mathrm{C}_{2} \mathrm{H}_{5} \mathrm{CHO}\right.$, Lykke et al. 2017). Recently, the first interstellar detection of the organohalogen $\mathrm{CH}_{3} \mathrm{Cl}$ was also reported towards this source (Fayolle et al. 2017).

In this Letter, we present the first interstellar detection of HONO. Further constraints on the nitrogen oxide chemistry towards IRAS 16293 are given, and a first attempt is made at modelling the HONO formation network.

\section{Observations and analysis}

Data from the Protostellar Interferometric Line Survey (PILS) of the low-mass protobinary IRAS 16293 were used to search for nitrogen oxides. This survey, taken with the Atacama Large Millimeter/submillimeter Array (ALMA), is fully described in Jørgensen et al. (2016). A short overview is given in this section. The survey covers part of Band 7 in the spectral range $329.147-362.896 \mathrm{GHz}$, at a spectral resolution of $0.2 \mathrm{~km} \mathrm{~s}^{-1}$, and with a sensitivity of $6-10 \mathrm{mJy} \mathrm{beam}^{-1}$ channel $^{-1}$ (i.e. 4-5 mJy beam ${ }^{-1} \mathrm{~km} \mathrm{~s}^{-1}$ ). A circular restoring beam of 0.5 was used to produce the final dataset. IRAS 16293 is a binary. HONO is identified towards source B, but not towards source A. Source B is analysed at a position offset by one beam with respect to the continuum peak position in the south-west direction $\left(\alpha_{\mathrm{J} 2000}=16^{\mathrm{h}} 32^{\mathrm{m}} 22^{\mathrm{s}} .58, \delta_{\mathrm{J} 2000}=-24^{\circ} 28^{\prime} 32.8^{\prime \prime}\right)$. The very narrow line widths $\left(1 \mathrm{~km} \mathrm{~s}^{-1}\right)$ at this position limit line blending and facilitate easier identification of molecules (e.g. Lykke et al. 2017).

To analyse the spectra and identify the HONO lines, the CASSIS line analysis software ${ }^{1}$, as well as the Jet Propulsion Laboratory (JPL ${ }^{2}$ ) spectroscopic database (Pickett et al. 1998) and the Cologne Database for Molecular Spectroscopy $\left(\mathrm{CDMS}^{3}\right.$; Müller et al. 2001, 2005) were used. The spectroscopy of HONO available in the JPL database was studied by Guilmot et al. (1993a,b) and Dehayem-Kamadjeu et al. (2005). HONO has two different conformers, trans and cis. The JPL entry assumes that the isomers are in thermal equilibrium. The trans/cis energy difference $\left(130.2 \mathrm{~cm}^{-1}\right)$ is from Varma \& Curl (1976). Since the spectra of IRAS 16293 are very line-rich, a careful check was performed to exclude blended or partially blended lines. To achieve this, we compared all lines tentatively identified as HONO with a template containing the lines of the molecules previously detected in this source (see Appendix A). Similar to previous PILS studies (e.g. Ligterink et al. 2018), the observed spectra were fitted with a synthetic spectrum, assuming local thermodynamic equilibrium (LTE) conditions, using a source size of 0.5 and a $V_{\mathrm{LSR}}$ velocity of $2.5 \mathrm{~km} \mathrm{~s}^{-1}$. As the line emission is coupled with dust emission in IRAS 16293, a correction to the background temperature $\left(T_{\mathrm{BG}}=21 \mathrm{~K}\right)$ was applied

\footnotetext{
CASSIS has been developed by IRAP-UPS/CNRS (http:// cassis.irap.omp.eu/)

2 http://spec.jpl.nasa.gov

https://cdms.astro.uni-koeln.de/
}

(see also Calcutt et al. 2018; Ligterink et al. 2018). A $\chi^{2}$ minimisation routine was employed to find the best-fit model to the observed data and derive the column density $(N)$ and excitation temperature ( $T_{\mathrm{ex}}$; see also Lykke et al. 2017; Calcutt et al. 2018; Ligterink et al. 2018). The grid covers excitation temperatures between 50 and $300 \mathrm{~K}$ with steps of $25 \mathrm{~K}$. After a first estimate of the column density, the grid was refined between $5 \times 10^{14}$ and $3 \times 10^{15} \mathrm{~cm}^{-2}$ with a step of $1 \times 10^{14} \mathrm{~cm}^{-2}$. To avoid any bias in the determination of the best-fit model with the $\chi^{2}$ calculation, we included some undetected transitions (333925.02, 348264.91 , and $358979.13 \mathrm{MHz}$ ) that are predicted to be above the noise limit for certain models in the grid.

\section{Observational results}

In total, we found 12 lines that could be identified as (trans-) HONO, which are not blended with any known species (see Fig. 1 and Table A.1). The intensities of nine out of these lines are higher or equal to $5 \sigma$. Two lines are 3 or $4 \sigma$ detections and one is a marginal $(2 \sigma)$ detection. The best-fit model is obtained for an excitation temperature of $100 \mathrm{~K}$ and a column density of $9 \times 10^{14} \mathrm{~cm}^{-2}$. The column density is not very sensitive to the excitation temperature. For a fixed excitation temperature of $300 \mathrm{~K}$, which is derived for several complex organic molecules (see Jørgensen et al. 2018), the best-fit column density is $1.4 \times 10^{15} \mathrm{~cm}^{-2}$, i.e. only $50 \%$ larger. Nevertheless, the model at $300 \mathrm{~K}$ overproduces some undetected lines at 333925.02, 348264.91, and 358979.13 MHz (Table A.2) and does not properly reproduce the line at $353468.14 \mathrm{MHz}$. The model at $300 \mathrm{~K}$ however better reproduces the line at $329519.48 \mathrm{MHz}$ than the model at $100 \mathrm{~K}$ (see Fig. 1). The best-fit excitation temperature of $100 \mathrm{~K}$ is consistent with the excitation temperature obtained for the other nitrogen oxides, especially NO (Ligterink et al. 2018). Three lines (329519.48, 329685.92, and $355001.15 \mathrm{GHz}$ ) have their fluxes underproduced by the best-fit model and could be blended with unknown species, although the first line is only detected at $3 \sigma$. Alternatively, it could be that for molecules with low-frequency vibrational modes such as HONO, the excitation does not need to be in LTE, but there could be infrared pumping for selected lines.

Lines of HONO were also searched towards other high sensitivity ALMA observations of the low-mass protostar IRAS 16293 . One line is present at $93008.6 \mathrm{MHz}$ in the lower spatial resolution data of the ALMA-PILS observations carried out in band 3 (Jørgensen et al. 2016, see Fig. 1). None are present in the band 6 data. According to our calculations, one HONO transition at $236131.076 \mathrm{MHz}$ should also be observed in the ALMA data presented in Taquet et al. (2018) with an intensity

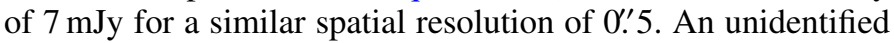
line is present at the same frequency, but its intensity is a factor 3 higher, which could mean that the observed line is blended with another species (see Fig. 1).

Maps of HONO (see Fig. 2) show that the emission is very compact around IRAS $16293 \mathrm{~B}$, similar to the majority of the molecules detected in this source, especially the complex organic molecules (see e.g. Coutens et al. 2016, 2018; Lykke et al. 2017) and NO (Ligterink et al. 2018).

Four other nitrogen-oxides, nitrosyl hydride (HNO), nitrosyl cation $\left(\mathrm{NO}^{+}\right)$, nitrogen dioxide $\left(\mathrm{NO}_{2}\right)$, and nitric acid $\left(\mathrm{HNO}_{3}\right)$ were searched for, but not identified (see Appendix $\mathrm{B}$ for details). Table 1 gives an overview of the derived column densities of the detected and unidentified species (upper limits) towards IRAS $16293 \mathrm{~B}$ and includes results on $\mathrm{NO}, \mathrm{N}_{2} \mathrm{O}$, and $\mathrm{NH}_{2} \mathrm{OH}$ from Ligterink et al. (2018). 

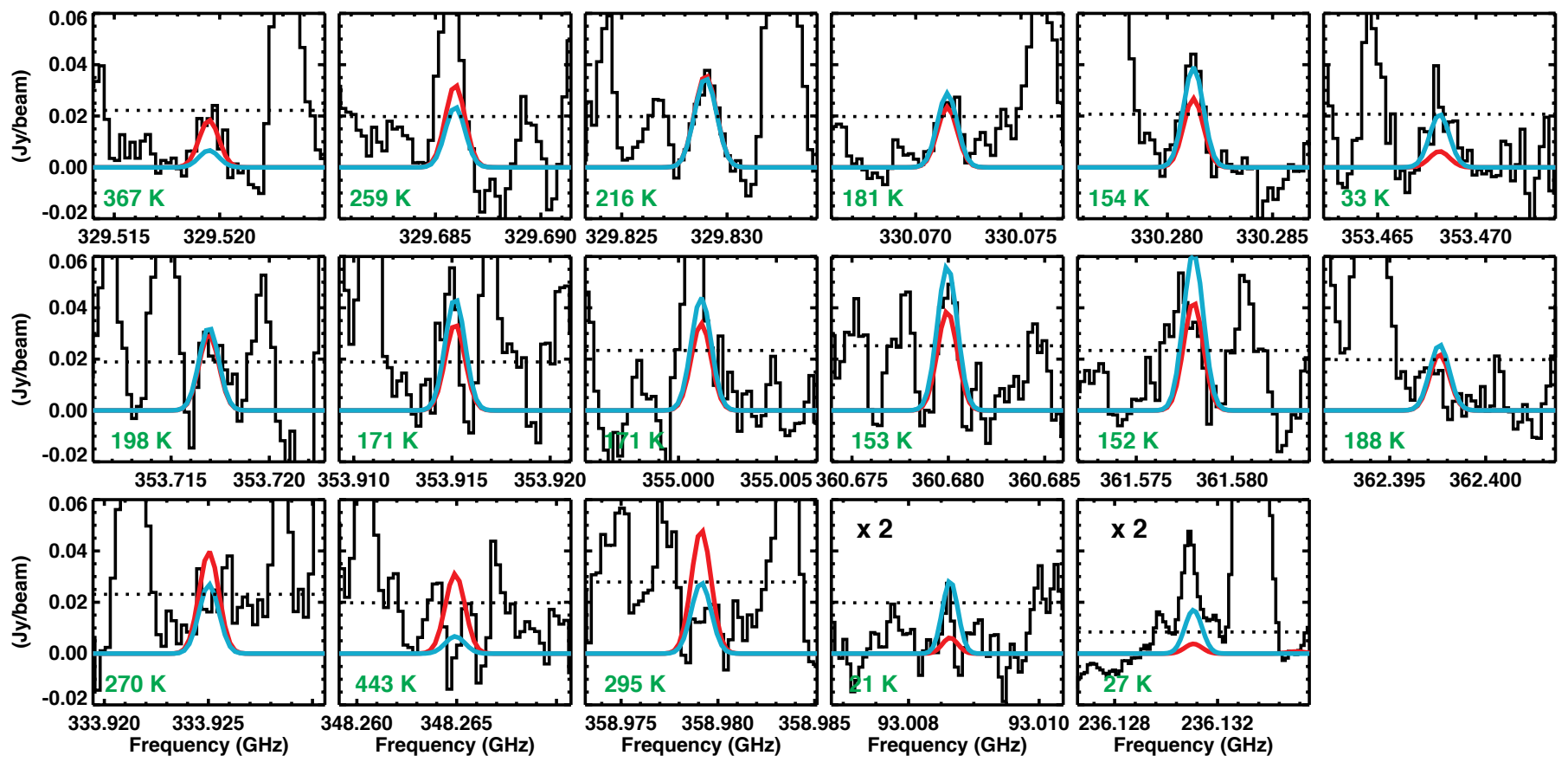

Fig. 1. Lines of HONO observed towards the protostar IRAS 16293 B (in black). The first 12 lines are the identified lines of HONO in the ALMAPILS band 7 survey. On the last row, the first 3 lines correspond to the undetected transitions that are used to constrain the best-fit model and the last two lines are those identified in other ALMA data (see Sect. 3 for more details). The $3 \sigma$ limit is indicated by a dotted line. The best-fit model with $T_{\text {ex }}=100 \mathrm{~K}$ is shown in blue, while the model in red corresponds to a higher $T_{\text {ex }}$ of $300 \mathrm{~K}$. The spectrum at $93 \mathrm{GHz}$ is extracted at the continuum peak position, given the lower spatial resolution of the data. The column density was multiplied by a factor 2 to take this difference into account (Jørgensen et al. 2016). The upper energy level is indicated in green in the bottom left corner of each panel.
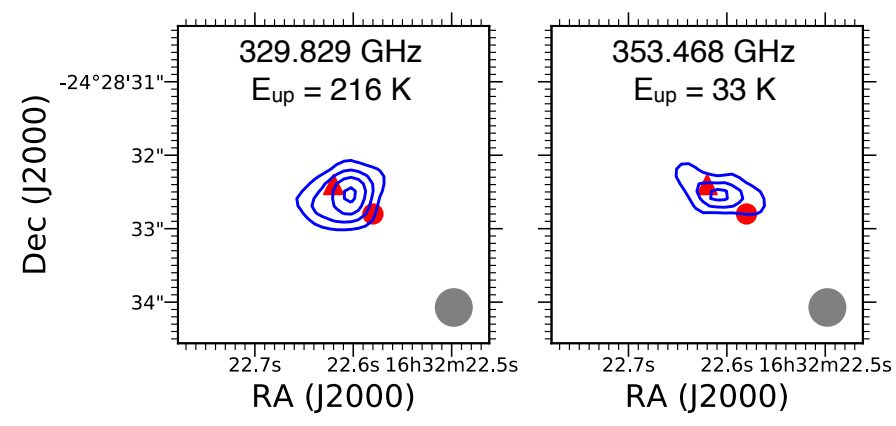

Fig. 2. Integrated intensity maps of two transitions of HONO towards IRAS $16293 \mathrm{~B}$. The position of the continuum peak is indicated with a red triangle, while the position analysed for IRAS 16293 B (full-beam offset) is indicated with a red circle. The beam size is indicated in grey in the bottom right corner. Left panel: contours are 5, 10, 15, and $20 \sigma$. Right panel: contour levels are 3,6, and $9 \sigma$.

\section{Chemical modelling of HONO}

To describe HONO and other $\mathrm{N}_{x} \mathrm{O}_{y} \mathrm{H}_{z}$ species, we updated the gas and grain chemical network used in Loison et al. (2019, and references therein) introducing various species such as $\mathrm{HONO}$, s- $\mathrm{HONO}, \mathrm{s}-\mathrm{HNO}_{2}$, s- $\mathrm{NH}_{2} \mathrm{O}$, s- $\mathrm{HNOH}, \mathrm{NH}_{2} \mathrm{OH}, s-\mathrm{NH}_{2} \mathrm{OH}$, $\mathrm{s}-\mathrm{NO}_{3}, \mathrm{~s}-\mathrm{HNO}_{3}$, and $\mathrm{s}-\mathrm{H}_{3} \mathrm{NO}_{2}$ (s- indicates species on grains). The reactions involving HONO are summarised in Table C.1 (we do not present the full network in this Letter). The chemistry of HONO is well described for Earth atmosphere chemistry where it is produced through the barrierless three body $\mathrm{OH}+\mathrm{NO}+\mathrm{M}$ reaction (Forster et al. 1995; Atkinson et al. 2004). However, this reaction is inefficient at the low densities of interstellar clouds and the radiative rate constant is negligible because of the small size of the system. All other known gas-phase reac-
Table 1. Column densities at the one beam offset position of IRAS 16293 B from the ALMA-PILS data.

\begin{tabular}{llcc}
\hline \hline Molecule & Formula & $N_{\text {tot }}^{\dagger}\left(\mathrm{cm}^{-2}\right)$ & $T_{\text {ex }}(\mathrm{K})$ \\
\hline Nitrous acid & $\mathrm{HONO}$ & $(9 \pm 5) \times 10^{14}$ & 100 \\
Nitric oxide & $\mathrm{NO}$ & $(2.0 \pm 0.5) \times 10^{16}$ & $40-150$ \\
Nitrous oxide & $\mathrm{N}_{2} \mathrm{O}$ & $\geq 4.0 \times 10^{16}$ & $25-350$ \\
Hydroxylamine & $\mathrm{NH}_{2} \mathrm{OH}$ & $\leq 4 \times 10^{14}$ & {$[100]$} \\
Nitrosyl hydride & $\mathrm{HNO}^{+}$ & $\leq 3 \times 10^{14}$ & {$[100]$} \\
Nitrogen dioxide & $\mathrm{NO}_{2}$ & $\leq 2 \times 10^{16}$ & {$[100]$} \\
Nitrosyl cation & $\mathrm{NO}^{+}$ & $\leq 2 \times 10^{14}$ & {$[100]$} \\
Nitric acid & $\mathrm{HNO}_{3}$ & $\leq 5 \times 10^{14}$ & {$[100]$} \\
\hline
\end{tabular}

Notes. All models assume LTE, FWHM of $1 \mathrm{~km} \mathrm{~s}^{-1}$, peak velocity $V_{\text {peak }}$ of $2.5 \pm 0.2 \mathrm{~km} \mathrm{~s}^{-1}$, and source size of 0.5 . $^{(\dagger)}$ The uncertainties are $3 \sigma$. Upper limits are also $3 \sigma$ and determined for an assumed $T_{\text {ex }}=100 \mathrm{~K}$, indicated with brackets in the table. ${ }^{(\ddagger)}$ Results from Ligterink et al. (2018).

tions producing $\mathrm{HONO}$ have negligible rates in the ISM. In our model, $\mathrm{HONO}$ is therefore produced on grains through $\mathrm{s}-\mathrm{O}+$ s-HNO, s-H + s- $\mathrm{NO}_{2}$, and s-OH + s-NO surface reactions, all of which are barrierless in the gas phase (Inomata \& Washida 1999; Du et al. 2004; Michael et al. 1979; Nguyen et al. 1998; Su et al. 2002; Forster et al. 1995; Atkinson et al. 2004).

This network was then used with the Nautilus gas-grain model (Ruaud et al. 2016), which computes the gas and grain chemistry. The chemical modelling was carried out in two steps as in similar previous studies of IRAS 16293 (see for instance Andron et al. 2018): a cold core phase (a gas and dust temperature of $10 \mathrm{~K}$, atomic $\mathrm{H}$ density of $10^{4} \mathrm{~cm}^{-3}$, visual 
Table 2. Abundances of HONO derived in IRAS 16293 B and with the chemical model.

\begin{tabular}{lcccccc}
\hline \hline & {$[\mathrm{HONO}] /[\mathrm{NO}]$} & {$[\mathrm{HONO}] /\left[\mathrm{N}_{2} \mathrm{O}\right]$} & {$[\mathrm{HONO}] /[\mathrm{HNO}]$} & {$[\mathrm{HONO}] /\left[\mathrm{NO}_{2}\right]$} & {$[\mathrm{HONO}] /\left[\mathrm{NH}_{2} \mathrm{OH}\right]$} & {$[\mathrm{HONO}] /\left[\mathrm{CH} \mathrm{H}_{3} \mathrm{OH}\right]$} \\
\hline IRAS 16293 B & $4.5 \times 10^{-2}$ & $\leq 2.3 \times 10^{-2, \dagger}$ & $\geq 3$ & $\geq 4.5 \times 10^{-2}$ & $\geq 2.3$ & $9 \times 10^{-5}$ \\
Chemical model & 71 & $2 \times 10^{-2}$ & $1 \times 10^{-2}$ & 533 & $1.7 \times 10^{-3}$ & $1.9 \times 10^{-4}$ \\
\hline
\end{tabular}

Notes. ${ }^{(\dagger)}$ Upper limit due to a lower limit on $\mathrm{N}_{2} \mathrm{O}$.

extinction $\left(A_{V}\right)$ of 15 , and cosmic-ray ionisation rate of $1.3 \times$ $10^{-17} \mathrm{~s}^{-1}$ ) during $10^{6} \mathrm{yr}$ followed by a collapse phase. For the collapse, we used the physical structure derived from a $1 \mathrm{D}$ radiative hydrodynamical model (see Aikawa et al. 2008) for parcels of material collapsing towards the central star. For these simulations, we used these parcels arriving at $62.4 \mathrm{au}$ at the end of the simulations (see Fig. 5 of Aikawa et al. 2008). The resulting abundance ratios at this radius at the end of the simulation are presented in Table 2.

In our model, HONO is essentially formed during the cold core phase. The final $\mathrm{HONO} / \mathrm{CH}_{3} \mathrm{OH}$ ratio predicted by the model is close to the observed value within a factor of 2 . The model ratios $\mathrm{HONO} / \mathrm{N}_{2} \mathrm{O}$ and $\mathrm{HONO} / \mathrm{NO}_{2}$ are also in agreement with the observed upper and lower limits, respectively. However, our model produces too little NO and too much $\mathrm{HNO}$ at high temperatures in the gas phase, resulting in a $\mathrm{HONO} / \mathrm{NO}$ ratio much larger and a $\mathrm{HONO} / \mathrm{HNO}$ ratio much smaller than the respective observed values. In our model, most of the NO reacts on grains with other radicals such as s-NH, when the temperature increases and NO becomes mobile. An explanation for the large $\mathrm{NO} / \mathrm{HNO}$ ratio observed in IRAS $16923 \mathrm{~B}$ could be that thermal desorption of s-HNO mainly results in its destruction to NO, owing to the weak H-NO bond of HNO (2.02 eV; Dixon 1996), as the formation of s-HNO is very likely due to the absence of a barrier for the s-H + s-NO reaction (Tsang \& Herron 1991; Nguyen et al. 2004; Washida et al. 1978; Glarborg et al. 1998). It should be noted that our model, as well as other published models, overproduce the abundance of $\mathrm{NH}_{2} \mathrm{OH}$, which has so far not been detected in the ISM (Pulliam et al. 2012; McGuire et al. 2015; Ligterink et al. 2018). It has been suggested that $\mathrm{NH}_{2} \mathrm{OH}$ cannot desorb without destruction by Jonusas \& Krim (2016), although this is in contradiction with the laboratory experiments of Congiu et al. (2012). Despite their differences, both experimental studies used very similar Temperature Programmed Desorption (TPD) set-ups and new experiments are therefore clearly needed to address these discrepancies. Other processes such as UV photodestruction of these species in ices could also explain the discrepancy between the model and observations (Fedoseev et al. 2016). In addition, the chemical network on grains and in the gas phase may not be fully relevant at protostellar temperatures. Some reactions with barriers, absent from the current network, may be significant.

\section{Conclusions}

We report the first detection of HONO in the ISM. This molecule, which is known to play a major role in the atmosphere of our planet, was found with ALMA towards the well-studied solar-type protostar IRAS 16293 B. This discovery complements the recent detection of $\mathrm{N}_{2} \mathrm{O}$ in the same source (Ligterink et al. 2018) and expands our knowledge of the chemical network of nitrogen oxides. Our updated model allows the abundances of HONO, $\mathrm{N}_{2} \mathrm{O}$, and $\mathrm{NO}_{2}$ to be reproduced satisfactorily, but not those of $\mathrm{NO}, \mathrm{HNO}$, and $\mathrm{NH}_{2} \mathrm{OH}$. One reason could be that $\mathrm{HNO}$ and $\mathrm{NH}_{2} \mathrm{OH}$ are destroyed upon thermal desorption, an occur- rence which deserves to be experimentally studied in detail. Other explanations could be that they are destroyed by UV photons in ices or that some grain surface or gas-phase reactions, potentially relevant at protostellar temperatures, are missing from the network.

Acknowledgements. This paper makes use of the ALMA data ADS/JAO. ALMA\#2013.1.00278.S. ALMA is a partnership of ESO (representing its member states), NSF (USA) and NINS (Japan), together with NRC (Canada) and NSC and ASIAA (Taiwan), in cooperation with the Republic of Chile. The Joint ALMA Observatory is operated by ESO, AUI/NRAO, and NAOJ. A.C. postdoctoral grant is funded by the ERC Starting Grant 3DICE (grant agreement 336474). V.W. and J.-C.L. acknowledge the CNRS programme Physique et Chimie du Milieu Interstellaire (PCMI) co-funded by the Centre National d'Etudes Spatiales (CNES). M.N.D. acknowledges the financial support of the SNSF Ambizione grant 180079, the Center for Space and Habitability (CSH) Fellowship and the IAU Gruber Foundation Fellowship. J.K.J. acknowledges support from ERC Consolidator Grant "S4F" (grant agreement 646908). Research at the Centre for Star and Planet Formation is funded by the Danish National Research Foundation.

\section{References}

Aikawa, Y., Wakelam, V., Garrod, R. T., \& Herbst, E. 2008, ApJ, 674, 984 Andron, I., Gratier, P., Majumdar, L., et al. 2018, MNRAS, 481, 5651

Atkinson, R., Baulch, D. L., Cox, R. A., et al. 2004, Atmos. Chem. Phys., 4, 1461

Burkholder, J. B., Mellouki, A., Talukdar, R., \& Ravishankara, A. 1992, Int. J. Chem. Kinet., 24, 711

Calcutt, H., Fiechter, M. R., Willis, E. R., et al. 2018, A\&A, 617, A95

Caux, E., Kahane, C., Castets, A., et al. 2011, A\&A, 532, A23

Cazaux, S., Tielens, A. G. G. M., Ceccarelli, C., et al. 2003, ApJ, 593, L51

Codella, C., Viti, S., Lefloch, B., et al. 2018, MNRAS, 474, 5694

Congiu, E., Fedoseev, G., Ioppolo, S., et al. 2012, ApJ, 750, L12

Coutens, A., Jørgensen, J. K., van der Wiel, M. H. D., et al. 2016, A\&A, 590, L6

Coutens, A., Willis, E. R., Garrod, R. T., et al. 2018, A\&A, 612, A107

Cox, R., \& Derwent, R. 1976, J. Photochem., 6, 23

de Barros, A. L. F., da Silveira, E. F., Fulvio, D., Boduch, P., \& Rothard, H. 2017, MNRAS, 465, 3281

Dehayem-Kamadjeu, A., Pirali, O., Orphal, J., Kleiner, I., \& Flaud, P.-M. 2005, J. Mol. Spectr., 234, 182

Dixon, R. N. 1996, J. Chem. Phys., 104, 6905

Du, B., Zhang, W., Feng, C., \& Zhou, Z. 2004, J. Mol. Struct. THEOCHEM, 712,101

Dzib, S. A., Ortiz-León, G. N., Hernández-Gómez, A., et al. 2018, A\&A, 614, A20

Fayolle, E. C., Öberg, K. I., Jørgensen, J. K., et al. 2017, Nat. Astron., 1, 703 Fedoseev, G., Ioppolo, S., Lamberts, T., et al. 2012, J. Chem. Phys., 137, 054714 Fedoseev, G., Chuang, K.-J., van Dishoeck, E. F., Ioppolo, S., \& Linnartz, H. 2016, MNRAS, 460, 4297

Florescu-Mitchell, A., \& Mitchell, J. 2006, Phys. Rep., 430, 277

Forster, R., Frost, M., Fulle, D., et al. 1995, J. Chem. Phys., 103, 2949

Fournier, J. A., Shuman, N. S., Melko, J. J., Ard, S. G., \& Viggiano, A. A. 2013,

J. Chem. Phys., 138, 154201

Geppert, W. D., Ehlerding, A., Hellberg, F., et al. 2004, ApJ, 613, 1302

Glarborg, P., Østberg, M., Alzueta, M. U., Dam-Johansen, K., \& Miller, J. A. 1998, Symp. (Int.) Combust., 27, 219

Gligorovski, S. 2016, J. Photochem. Photobiol. A Chem., 314, 1

Guilmot, J. M., Godefroid, M., \& Herman, M. 1993a, J. Mol. Spectr., 160, 387 Guilmot, J. M., Melen, F., \& Herman, M. 1993b, J. Mol. Spectr., 160, 401 Herbst, E., \& Leung, C. M. 1986, ApJ, 310, 378

Hsu, C.-C., Lin, M., Mebel, A., \& Melius, C. 1997, J. Chem. Phys. A, 101, 60 Inomata, S., \& Washida, N. 1999, J. Phys. Chem. A, 103, 5023

Jenkin, M., \& Cox, R. 1987, Chem. Phys. Lett., 137, 548 
A. Coutens et al.: First detection of HONO in the interstellar medium

Jenkin, M., Cox, R., \& Williams, D. 1988, Atmos. Environ., 22, 487 Jonusas, M., \& Krim, L. 2016, MNRAS, 459, 1977

Jørgensen, J. K., Favre, C., Bisschop, S. E., et al. 2012, ApJ, 757, L4 Jørgensen, J. K., van der Wiel, M. H. D., Coutens, A., et al. 2016, A\&A, 595, A117

Jørgensen, J. K., Müller, H. S. P., Calcutt, H., et al. 2018, A\&A, 620, A170

Joshi, P. R., Zins, E.-L., \& Krim, L. 2012, MNRAS, 419, 1713

Kahane, C., Ceccarelli, C., Faure, A., \& Caux, E. 2013, ApJ, 763, L38

Lee, B. H., Wood, E. C., Herndon, S. C., et al. 2013, J. Geophys. Res. (Atmos.), 118,12

Ligterink, N. F. W., Coutens, A., Kofman, V., et al. 2017, MNRAS, 469, 2219

Ligterink, N. F. W., Calcutt, H., Coutens, A., et al. 2018, A\&A, 619, A28

Liszt, H. S., \& Turner, B. E. 1978, ApJ, 224, L73

Loison, J.-C., Wakelam, V., Gratier, P., et al. 2019, MNRAS, in press [arXiv:1902 . 08840]

Lykke, J. M., Coutens, A., Jørgensen, J. K., et al. 2017, A\&A, 597, A53

Martín-Doménech, R., Rivilla, V. M., Jiménez-Serra, I., et al. 2017, MNRAS, 469, 2230

McGonagle, D., Ziurys, L. M., Irvine, W. M., \& Minh, Y. C. 1990, ApJ, 359, 121

McGuire, B. A., Carroll, P. B., Dollhopf, N. M., et al. 2015, ApJ, 812, 76

Michael, J. V., Nava, D. F., Payne, W. A., Lee, J. H., \& Stief, L. J. 1979, J. Phys. Chem., 83, 2818

Müller, H. S. P., Thorwirth, S., Roth, D. A., \& Winnewisser, G. 2001, A\&A, 370, L49

Müller, H. S. P., Schlöder, F., Stutzki, J., \& Winnewisser, G. 2005, J. Mol. Struct., 742,215

Nejad, L. A. M., Williams, D. A., \& Charnley, S. B. 1990, MNRAS, 246, 183
Nguyen, M. T., Sumathi, R., Sengupta, D., \& Peeters, J. 1998, Chem. Phys., 230, 1

Nguyen, H., Zhang, S., Peeters, J., Truong, T., \& Nguyen, M. 2004, Chem. Phys. Lett., 388, 94

Pickett, H. M., Poynter, R. L., Cohen, E. A., et al. 1998, J. Quant. Spectr. Rad. Transf., 60, 883

Pineau des Forêts, G., Roueff, E., \& Flower, D. R. 1990, MNRAS, 244, 668

Plessis, S., Carrasco, N., Dobrijevic, M., \& Pernot, P. 2012, Icarus, 219, 254

Possanzini, M., Buttini, P., \& Di Palo, V. 1988, Sci. Total Environ., 74, 111

Pulliam, R. L., McGuire, B. A., \& Remijan, A. J. 2012, ApJ, 751, 1

Ren, X., Harder, H., Martinez, M., et al. 2003, Atoms. Environ., 37, 3639

Ruaud, M., Wakelam, V., \& Hersant, F. 2016, MNRAS, 459, 3756

Snyder, L. E., Kuan, Y.-J., Ziurys, L. M., \& Hollis, J. M. 1993, ApJ, 403, L17

Su, M. C., Kumaran, S. S., Lim, K. P., et al. 2002, J. Phys. Chem. A, 106, 8261

Taquet, V., van Dishoeck, E. F., Swayne, M., et al. 2018, A\&A, 618, A11

Tsang, W., \& Herron, J. 1991, J. Phys. Chem. Ref. Data, 20, 609

van Dishoeck, E. F., Blake, G. A., Jansen, D. J., \& Groesbeck, T. D. 1995, ApJ, 447, 760

Varma, R., \& Curl, R. F. 1976, J. Phys. Chem., 80, 402

Visser, R., Doty, S. D., \& van Dishoeck, E. F. 2011, A\&A, 534, A132

Wakelam, V., Smith, I., Herbst, E., et al. 2010, Space Sci. Rev., 156, 13

Wakelam, V., Herbst, E., Loison, J.-C., et al. 2012, ApJS, 199, 21

Washida, N., Akimoto, H., \& Okuda, M. 1978, J. Phys. Chem., 82, 2293

Zhang, L., Wang, T., Zhang, Q., et al. 2016, J. Geophys. Res. (Atmos.), 121, 3645

Ziurys, L. M., McGonagle, D., Minh, Y., \& Irvine, W. M. 1991, ApJ, 373, 535

Ziurys, L. M., Apponi, A. J., Hollis, J. M., \& Snyder, L. E. 1994, ApJ, 436, L181 


\section{Appendix A: Lines of HONO}

The detected HONO transitions that are not found to be blended with known species are listed in Table A.1. To check the potential blending of the HONO lines with other species, we defined a template based on the molecules previously identified in the ALMA-PILS survey. This template includes the following species (ranked by mass): $\mathrm{CCH}, \mathrm{HCN}, \mathrm{HNC}$, $\mathrm{H}^{13} \mathrm{CN}, \mathrm{HC}^{15} \mathrm{~N}, \mathrm{DNC}, \mathrm{CO},{ }^{13} \mathrm{CO}, \mathrm{C}^{17} \mathrm{O}, \mathrm{H}^{13} \mathrm{C}^{15} \mathrm{~N}, \mathrm{CH}_{2} \mathrm{NH}$, $\mathrm{NO}, \mathrm{C}^{18} \mathrm{O}, \mathrm{DCO}^{+}, \mathrm{H}_{2} \mathrm{CO}, \mathrm{HDCO}, \mathrm{H}_{2}^{13} \mathrm{CO}, \mathrm{H}_{2} \mathrm{C}^{17} \mathrm{O}, \mathrm{D}_{2} \mathrm{CO}$, $\mathrm{H}_{2} \mathrm{C}^{18} \mathrm{O}, \mathrm{CH}_{3} \mathrm{OH}, \mathrm{CH}_{2} \mathrm{DOH}, \mathrm{CH}_{3} \mathrm{OD},{ }^{13} \mathrm{CH}_{3} \mathrm{OH}, \mathrm{D}_{2}^{13} \mathrm{CO}$, $\mathrm{H}_{2} \mathrm{~S}, \mathrm{CH}_{3}^{18} \mathrm{OH}$, HDS, $\mathrm{HD}^{34} \mathrm{~S}, \mathrm{c}-\mathrm{C}_{3} \mathrm{H}_{2}, \mathrm{CH}_{3} \mathrm{CCH}, \mathrm{CH}_{3} \mathrm{CN}$, $\mathrm{CH}_{3} \mathrm{NC}, \mathrm{NH}_{2} \mathrm{CN}, \mathrm{H}_{2} \mathrm{CCO},{ }^{13} \mathrm{CH}_{3} \mathrm{CN}, \mathrm{CH}_{3}^{13} \mathrm{CN}, \mathrm{CH}_{3} \mathrm{C}^{15} \mathrm{~N}$, $\mathrm{CH}_{2} \mathrm{DCN}, \mathrm{H}_{2} \mathrm{C}^{13} \mathrm{CO}, \mathrm{H}_{2}^{13} \mathrm{CCO}, \mathrm{HDCCO}, \mathrm{HNCO}, \mathrm{CHD}_{2} \mathrm{CN}$, $\mathrm{NH}_{2}^{13} \mathrm{CN}, \quad \mathrm{NHDCN}, \mathrm{CH}_{3} \mathrm{CHO}, \mathrm{N}_{2} \mathrm{O}, \quad \mathrm{DNCO}, \mathrm{HN}^{13} \mathrm{CO}$,
$\mathrm{CS}, \quad \mathrm{c}-\mathrm{C}_{2} \mathrm{H}_{4} \mathrm{O}, \quad \mathrm{SiO}, \quad \mathrm{CH}_{3} \mathrm{CDO}, \quad{ }^{13} \mathrm{CH}_{3} \mathrm{CHO}, \quad \mathrm{CH}_{3}^{13} \mathrm{CHO}$, $\mathrm{C}^{33} \mathrm{~S}, \mathrm{NH}_{2} \mathrm{CHO}, \mathrm{C}^{34} \mathrm{~S}, \mathrm{t}-\mathrm{HCOOH}, \mathrm{H}_{2} \mathrm{CS}, \mathrm{NH}_{2}^{13} \mathrm{CHO}$, cisNHDCHO, trans-NHDCHO, $\mathrm{NH}_{2} \mathrm{CDO}, \mathrm{CH}_{3} \mathrm{OCH}_{3}, \mathrm{C}_{2} \mathrm{H}_{5} \mathrm{OH}$, $\mathrm{DCOOH}$, HCOOD, t- $\mathrm{H}^{13} \mathrm{COOH}$, HDCS, a- $\mathrm{CH}_{3}^{13} \mathrm{CH}_{2} \mathrm{OH}$, a- ${ }^{13} \mathrm{CH}_{3} \mathrm{CH}_{2} \mathrm{OH}$, a- $\mathrm{CH}_{3} \mathrm{CH}_{2} \mathrm{OD}$, a- $\mathrm{CH}_{3} \mathrm{CHDOH}$, a-a$\mathrm{CH}_{2} \mathrm{DCH}_{2} \mathrm{OH}$, a-s- $\mathrm{CH}_{2} \mathrm{DCH}_{2} \mathrm{OH},{ }^{13} \mathrm{CH}_{3} \mathrm{OCH}_{3}, \mathrm{a}-\mathrm{CH}_{2} \mathrm{DOCH}_{3}$, sym- $\mathrm{CH}_{2} \mathrm{DOCH}_{3}, \mathrm{SO}, \mathrm{C}^{36} \mathrm{~S}, \mathrm{CH}_{3} \mathrm{SH}, \mathrm{CH}_{3}^{35} \mathrm{Cl}, \mathrm{HC}_{3} \mathrm{~N}, \mathrm{CH}_{3}^{37} \mathrm{Cl}$, $\mathrm{C}_{2} \mathrm{H}_{3} \mathrm{CN}, \quad \mathrm{C}_{2} \mathrm{H}_{5} \mathrm{CN}, \quad \mathrm{CH}_{3} \mathrm{NCO}, \mathrm{CH}_{3} \mathrm{COCH}_{3}, \mathrm{C}_{2} \mathrm{H}_{5} \mathrm{CHO}$, $\mathrm{CH}_{3} \mathrm{OCHO}, \mathrm{CH}_{2}(\mathrm{OH}) \mathrm{CHO}$, OCS, $\mathrm{CH}_{3} \mathrm{COOH}, \mathrm{O}^{13} \mathrm{CS}$, $\mathrm{OC}^{33} \mathrm{~S}, \quad \mathrm{CH}_{2}(\mathrm{OH}){ }^{13} \mathrm{CHO},{ }^{13} \mathrm{CH}_{2}(\mathrm{OH}) \mathrm{CHO}, \mathrm{CH}_{3} \mathrm{O}^{13} \mathrm{CHO}$, $\mathrm{CH}_{2}(\mathrm{OD}) \mathrm{CHO}, \mathrm{CHD}(\mathrm{OH}) \mathrm{CHO}, \mathrm{CH}_{2}(\mathrm{OH}) \mathrm{CDO}, \mathrm{CH}_{3} \mathrm{OCDO}$, $\mathrm{CH}_{2} \mathrm{DOCHO}, \mathrm{CHD}_{2} \mathrm{OCHO}, \mathrm{aGg}$ ' $-\left(\mathrm{CH}_{2} \mathrm{OH}\right)_{2}, \mathrm{gGg}$ ' $-\left(\mathrm{CH}_{2} \mathrm{OH}\right)_{2}$, $\mathrm{OC}^{34} \mathrm{~S},{ }^{18} \mathrm{OCS}, \mathrm{CHD}{ }_{2} \mathrm{OCHO}, \mathrm{SO}_{2}$, and ${ }^{34} \mathrm{SO}_{2}$. Figure A.1 presents the HONO lines over a larger spectral range with the overlaid template model in green and the HONO model in red.

Table A.1. List of the detected and unblended HONO transitions.

\begin{tabular}{cccccc}
\hline \hline Molecule & $\begin{array}{c}\text { Transition } \\
(\mathrm{MHz})\end{array}$ & $\begin{array}{c}\text { Frequency } \\
(\mathrm{K})\end{array}$ & $\begin{array}{c}E_{\mathrm{up}} \\
\left(\mathrm{s}^{-1}\right)\end{array}$ & $A_{\mathrm{ij}}$ & $g_{\text {up }}$ \\
\hline trans-HONO & $1486-1385$ & 329519.5 & 367.2 & $2.57 \times 10^{-4}$ & 29 \\
trans-HONO & $1487-1386$ & 329519.5 & 367.2 & $2.57 \times 10^{-4}$ & 29 \\
trans-HONO & $1468-1367$ & 329685.9 & 258.6 & $3.12 \times 10^{-4}$ & 29 \\
trans-HONO & $1469-1368$ & 329685.9 & 258.6 & $3.12 \times 10^{-4}$ & 29 \\
trans-HONO & $14510-1359$ & 329828.8 & 215.9 & $3.34 \times 10^{-4}$ & 29 \\
trans-HONO & $1459-1358$ & 329829.2 & 215.9 & $3.34 \times 10^{-4}$ & 29 \\
trans-HONO & $14411-13410$ & 330071.5 & 181.0 & $3.52 \times 10^{-4}$ & 29 \\
trans-HONO & $14312-13311$ & 330281.2 & 153.8 & $3.67 \times 10^{-4}$ & 29 \\
trans-HONO & $524-413$ & 353468.1 & 32.5 & $1.50 \times 10^{-4}$ & 11 \\
trans-HONO & $15412-14411$ & 353716.9 & 198.0 & $4.40 \times 10^{-4}$ & 31 \\
trans-HONO & $15313-14312$ & 353915.2 & 170.8 & $4.55 \times 10^{-4}$ & 31 \\
trans-HONO & $15312-14311$ & 355001.2 & 171.0 & $4.59 \times 10^{-4}$ & 31 \\
trans-HONO & $15213-14212$ & 360679.9 & 152.9 & $4.93 \times 10^{-4}$ & 31 \\
trans-HONO & $16116-15115$ & 361578.0 & 151.9 & $5.04 \times 10^{-4}$ & 33 \\
trans-HONO & $17216-17117$ & 362397.6 & 187.8 & $2.77 \times 10^{-4}$ & 35 \\
\hline
\end{tabular}

Notes. Quantum numbers are given as $J^{\prime} K_{a}^{\prime} K_{c}^{\prime}-J^{\prime \prime} K_{a}^{\prime \prime} K_{c}^{\prime \prime}$.

Table A.2. List of the undetected HONO transitions used in the $\chi^{2}$ calculation.

\begin{tabular}{rccccc}
\hline \hline Species & $\begin{array}{c}\text { Transition } \\
(\mathrm{MHz})\end{array}$ & $\begin{array}{c}\text { Frequency } \\
(\mathrm{K})\end{array}$ & $\begin{array}{c}E_{\mathrm{up}} \\
\left(\mathrm{s}^{-1}\right)\end{array}$ & $A_{\mathrm{ij}}$ & $g_{\text {up }}$ \\
\hline trans-HONO & $21120-21021$ & 333925.0 & 270.3 & $5.42 \times 10^{-4}$ & 43 \\
cis-HONO & $20119-20020$ & 348264.9 & 443.2 & $7.87 \times 10^{-4}$ & 41 \\
trans-HONO & $22121-22022$ & 358979.1 & 295.3 & $6.82 \times 10^{-4}$ & 45 \\
\hline
\end{tabular}

Notes. Quantum numbers are given as $J^{\prime} K_{a}^{\prime} K_{c}^{\prime}-J^{\prime \prime} K_{a}^{\prime \prime} K_{c}^{\prime \prime}$. 

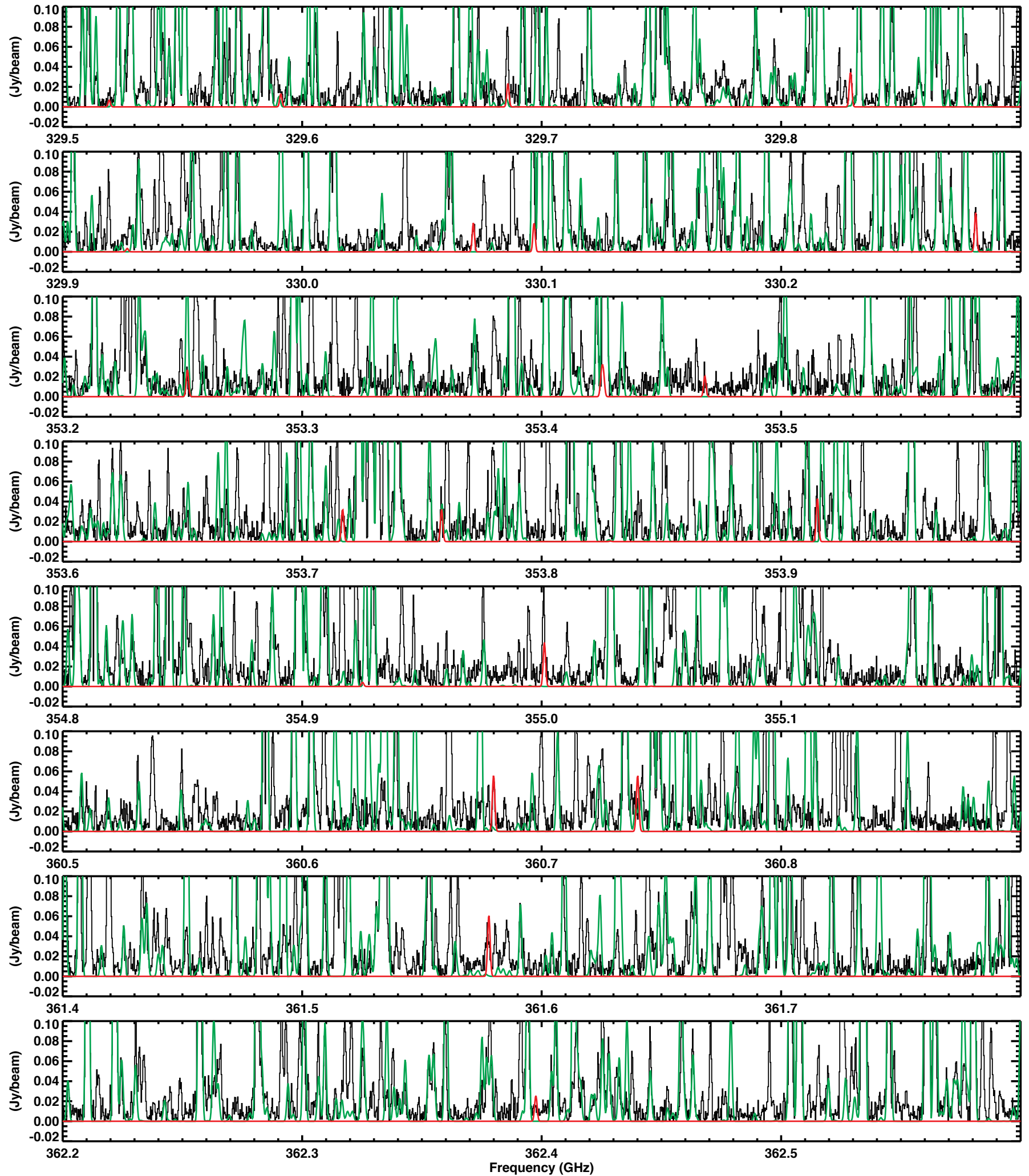

Fig. A.1. Lines of HONO observed towards the protostar IRAS 16293 B over a larger spectral range. The HONO best-fit model is shown in red, while the template model used to check the potential blending of the lines is overlaid in green. 


\section{Appendix B: Upper limit determination of HNO,} $\mathrm{NO}^{+}, \mathrm{NO}_{2}$, and $\mathrm{HNO}_{3}$

The molecules $\mathrm{HNO}, \mathrm{NO}^{+}, \mathrm{NO}_{2}$, and $\mathrm{HNO}_{3}$ were searched for in the PILS data without success. Upper limit column densities of $3 \sigma$ were determined for $T_{\mathrm{ex}}=100 \mathrm{~K}$. When possible, linefree regions of the observed data, where transitions are expected, were used. For HNO, the $4_{1,3}-3_{1,2}$ transition at $332106.6 \mathrm{MHz}$, which is close to the transition of an unidentified species, was used. For $\mathrm{NO}^{+}$, only the $3-2$ transition at $357.564 \mathrm{GHz}$ is covered in the PILS range. It is found to be blended with a line of ethylene glycol. We determined a conservative upper limit based on the total flux of this line. For $\mathrm{NO}_{2}$, the undetected transitions at 348062.5 and $348820.7 \mathrm{MHz}$ were used. For $\mathrm{HNO}_{3}$, many undetected lines are covered in the spectral range of the PILS survey. The upper limit was derived based on the brightest lines predicted in line-free regions. At $T_{\mathrm{ex}}=100 \mathrm{~K}$, this yields $3 \sigma$ upper limit column densities of $3 \times 10^{14}, 2 \times 10^{14}, 2 \times 10^{16}$, and $5 \times 10^{14} \mathrm{~cm}^{-2}$ for $\mathrm{HNO}, \mathrm{NO}^{+}, \mathrm{NO}_{2}$, and $\mathrm{HNO}_{3}$, respectively.

\section{Appendix C: Chemical reactions for HONO}

The reactions involving HONO are listed in Table C.1. 


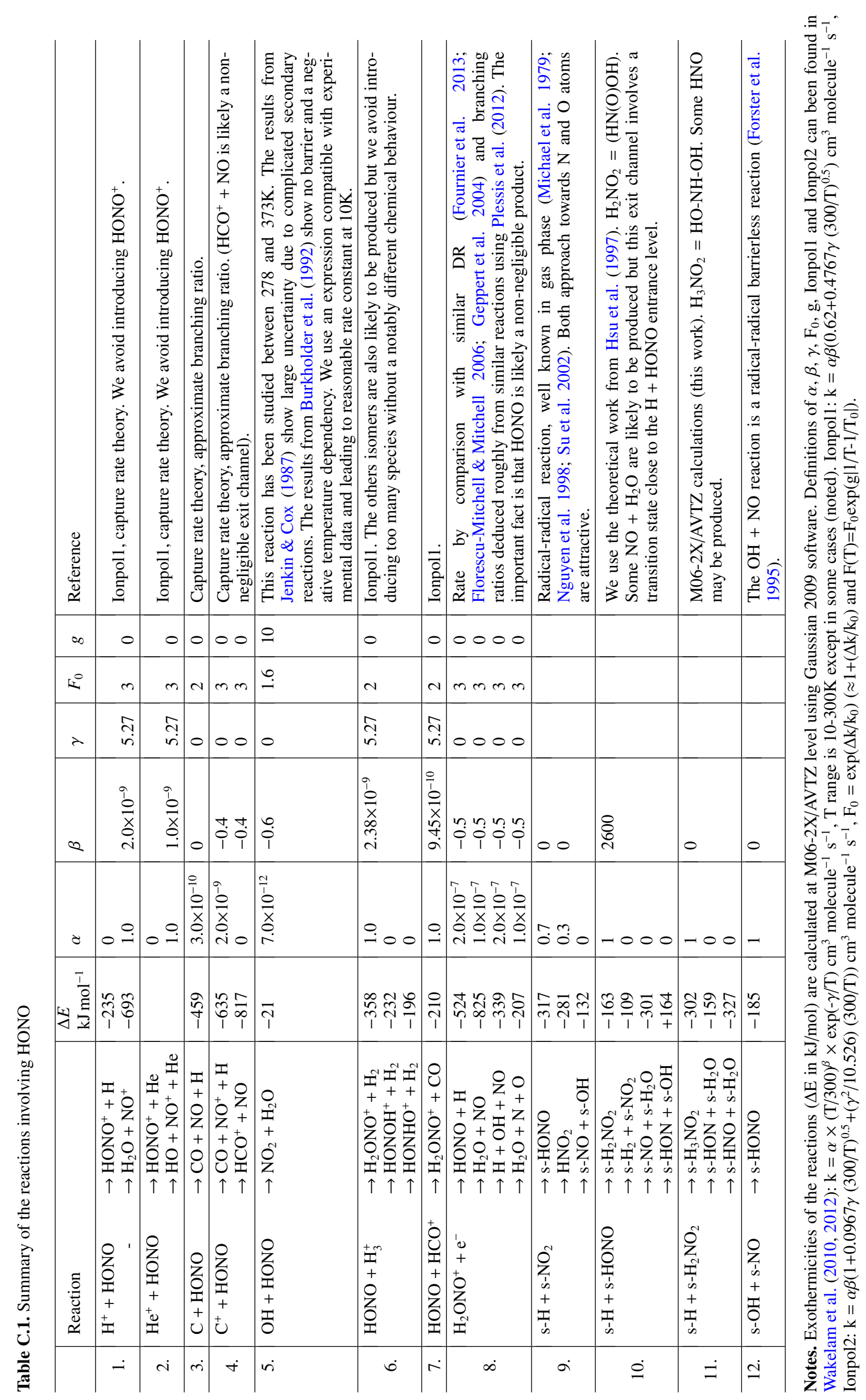

